\title{
El emprendimiento, una alternativa prioritaria para Egresados de una IES
}

\author{
Entrepreneurship, a priority alternative for graduates of an HEI
}

Roselio Lima Vázquez ${ }^{a}$, Margarita Aida cruz García ${ }^{b}$

\begin{abstract}
:
Currently, higher education schools or Higher Education Institutions (HEI), should be concerned with covering the work needs of their graduates, to formulate a broad vision of the Labor Market, not only offering studies or careers that are the best paid, Finally, those that are the worst paid, should also be the object of study and work alternative. In the case, the main concern will be necessary for aspects such as the remuneration of graduates of an HEI, for better and worse paid careers, falling mainly on the culture of entrepreneurship, of the educational offer and their graduation profile, of linking HEIs with both regulatory and support institutions in terms of teaching-learning, employers and labor demands with the formation of their own educational offerings.
\end{abstract}

Keywords:

Higher Education Institutions (HEI), Entrepreneurship, Professionals, Exit Profile, Labor Market

\section{Resumen:}

En la actualidad, las escuelas de enseñanza superior o Instituciones de Enseñanza Superior (IES), deben preocuparse por cubrir la necesidad laboral de sus egresados, de formularles una amplia visión del Mercado Laboral, no solo ofreciendo estudios o carre ras que sean las mejores pagadas, pues finalmente aquellas que son las peores pagadas, también deben ser objeto de estudio y alternativa laboral. Para el caso, será necesario la preocupación principal por aspectos como la remuneración de los egresados de una IES, por carreras mejor y peor pagadas, recayendo principalmente en la cultura del emprendimiento, de la of erta educativa y su perfil de egreso, de la vinculación de las IES con instituciones tanto reguladoras como de apoyo en materia de enseñanza-aprendizaje, de empleadores y de las demandas laborales con la conformación de las propias ofertas educativas.

\section{Palabras Clave:}

Instituciones de Enseñanza Superior (IES), Emprendimiento, Profesionistas, Perfil de Egresos, Mercado Laboral

\section{Introducción}

Lorem Conforme a estadísticas e indicadores de la relación laboral y del emprendimiento, obtenidos de publicaciones e investigaciones consultadas en bases de datos primarios como el INEGI y la OCDE; las profesiones del área de Ciencias Económico Administrativo (CEA) y Sociales, son las mejores pagadas y más empleadas, no obstante, es ilógico dejar a la deriva aquellos que no alcanzan a ser empleados, pues estos podrían: primero auto empelarse, y segundo; ayudar a otros profesionistas a auto emplearse, esto a través de la consultoría y hacer que se logren más y mejores empresas, aportando una mejor condición de vida.

Para ello, se abordan los temas relacionados con el emprendimiento en los estudiantes y después egresados de una IES, basados en diferentes estadísticas e investigaciones publicadas, así por ejemplo, la investigación publicada porel IMEF (Institu to Mexicano de Ejecutivos en Finanzas), aconseja que se Fortalezcan las Carreras Técnicas, es decir, que el futuro de México, está sustentado en obreros, distinguidos como técnicos superiores, mostrando resultados en los que estos técnicos superiores superan a los profesionistas universitarios peores remunerados económicamente.

\footnotetext{
a Profesor de Asignatura en la Universidad Autónoma de Tlaxcala, adscrito a la Unidad Académica Multidisciplina ria Campus Calpulalpan, https://orcid.org/0000-0003-1588-4921, e mail: rosliva@uatx.mx

b Profesor-Investigadora-, coordinadora del programa educativo en Contaduría Pública de la Unidad Académica Multidisciplinaria Campus Calpulalpan, https://orcid.org/0000-0003-1588-4921, Email: cruzcampus06@ hotmail.com
} 
Tomando en cuenta estadísticas y publicaciones de organismos internacionales y nacionales, que muestren el comportamiento de la situación laboral de la educación superior, por ejemplo: los rangos en las edades, los que tienen título universitario, aquellos que estudian un posgrado, egresados que laboran conforme a su perfil de egresos, y en contraste quienes se encuentran en desempleo; en fin, indicadores y resultados que son la base su explicación.

\section{El Fortalecimiento de las Carreras Técnicas el futuro de México}

En México existen distintos informes e investigaciones soportados en datos del Instituto Nacional de Estadística y Geografía (INEGI). En su mayoría, coinciden en que las carreras con el mayor número de trabajadores son: La administración y gestión de empresas, Derecho, Contabilidad y Fiscalización, que suman, por el contrario, las carreras con menor número de ocupados siendo la de Teología, Servicios de Transporte y Deportes.

Los profesionistas solo representan el $15.1 \%$ de la fuerza laboral activa del país; los trabajadores formales representan $42 \%$ mientras que los informales componen $58 \%$ generando el $24.8 \%$ del PIB, mediante una publicación en efectuada por el IMCO (Institu to Mexicano para la Competitividad), De los 10 puestos más difíciles de cubriren México, 7 se ofertan en la educación técnica, una oportunidad para enfrentar la deman da de capital humano especializado [1].

El mismo instituto especifica que las carreras técnicas mejor pagadas, como las relacionadas con la Construcción e ingeniería civil y los Servicios de Transporte, ganan en promedio más que las universitarias peor pagadas, como lo son: Los Deportes o Filosofía y Ética. Complementa que estu diar una licenciatura implica un aumento considerable en el salario de una persona, así, un licenciado gana en promedio, $80 \%$ más que alguien que solo terminó el bachillerato, por el contrario, manifiesta que terminar una licenciatura reduce en $51 \%$ el riesgo de estar empleado en el sector informal en comparación de los egresados de bachillerato [1].

Si bien se han hecho investigaciones por distintos y variados organismos tanto públicos como privados, es cierto que no se debe ocultar la razón de quererse superar como persona en el contexto educativo, máxime que cada vez el nivel académico es mayormente exigible como indicador internacional.
En la publicación emitida por la OCDE, México tiene una de las mayores proporciones de estudiantes que ingresan a la educación superior en el campo de la ciencia entre los países miembros de esta organización [2].

En el 2015 , el $32 \%$ de los alumnos de nuevo ingreso a la educación superior eligieron las áreas de estudio relacionadas con la Ciencia, la Tecnología, la Ingeniería y las Matemáticas, colocándose 5 puntos porcentuales arriba del promedio de la OCDE, situando a México entre los seis primeros países de la OCDE [2].

En la educación superior para adultos entre 25 y 34 años en los países miembros de la OCDE se coloca en el $43 \%$ quienes tenían un título universitario en 2016. En contraste, la población en esa edad sin educación media superior alcanza el 16\%. En promedio entre los países de la OCDE, el $23 \%$ de las personas de 25 a 64 años con educación superior tiene título universitario relacionado con áreas de negocios, administración o derecho. El 17\% tiene un título relacionado con ingeniería, construcción y manufactura; el $5 \%$ en ciencias naturales, estadística y matemática y el 4\% en tecnologías de la información y comunicación. El nivel de desempleo en adultos jóvenes entre 25 y 34 años que no finalizaron sus estudios universitarios fue del 17\%, mientras que para quienes sí los finalizaron, el desempleo fue de $9 \%$ [2].

Las tasas de la matrícula siguen siendo inferiores a promedio de la OCDE. El gasto en instituciones educativas de México fue de $5.4 \%$, similar al de los países latinoamericanos y está por arriba del promedio de la OCDE, $5.2 \%$ [2].

Aunque se distingue que el gasto de México por estudiante es de 3 mil 703 mil dólares, lo que representa el más bajos del promedio de los miembros de la OCDE, siendo este de 10 mil 759 dólares [2].

En México apenas el 17\% de las personas de entre 25 a 64 años de edad, había cursado la educación superior en el 2016, el porcentaje más bajo entre los países de la OCDE, con un promedio de $37 \%$. Para posgrados, solo $1 \%$ de los mexicanos de dicho rango de edad tienen una maestría o equivalente, mientras que menos del $1 \%$ tienen un doctorado [2].

Se muestran las estadísticas en la siguiente tabla, respecto a la situación laboral en México, de la cual, se puede observar que entre mejor preparado se este, menos porcentaje de informalidad y también menor tasa de desocupación. 


\begin{tabular}{|c|c|c|c|c|c|c|}
\hline Nivel & $\begin{array}{l}\overline{\widetilde{\sigma}} \\
\end{array}$ & $\begin{array}{c}\text { Salario } \\
\text { promedio } \\
\text { Mensual }\end{array}$ & $\begin{array}{r} \\
\frac{0}{0} \\
0 \\
0 \\
0 \\
0 \\
0 \\
0 \\
0 \\
0 \\
0 \\
0\end{array}$ & $\begin{array}{l}\frac{\mathscr{E}}{\sigma N} \\
\frac{\tilde{E}}{0} \\
\stackrel{0}{L}\end{array}$ & 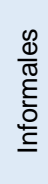 & 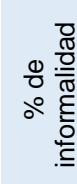 \\
\hline 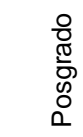 & 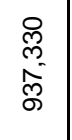 & 18,926 & 2.12 & 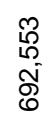 & $\begin{array}{l}\infty \\
\stackrel{\infty}{\sim} \\
\stackrel{\infty}{\infty} \\
\infty\end{array}$ & 11.30 \\
\hline 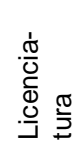 & $\begin{array}{l}1 \\
\infty \\
\infty \\
\infty \\
0 \\
0 \\
0\end{array}$ & 11,327 & 5.08 & $\begin{array}{l}\mathscr{8} \\
\varnothing \\
\infty \\
\infty \\
\infty \\
\infty \\
\infty\end{array}$ & $\begin{array}{l}\mathscr{8} \\
\mathscr{6} \\
\infty \\
00 \\
0 \\
0 \\
\end{array}$ & 22.28 \\
\hline 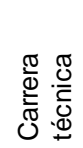 & 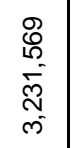 & 6,891 & 3.73 & 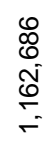 & $\begin{array}{l}\stackrel{L}{0} \\
\stackrel{N}{N} \\
\stackrel{N}{N}\end{array}$ & 38.38 \\
\hline 응 & 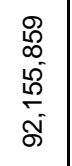 & 6,185 & 3.88 & $\begin{array}{l}\bar{\delta} \\
\text { స్ } \\
\text { స్ } \\
\text { Ñ }\end{array}$ & $\begin{array}{l}N \\
\text { E } \\
\text { J } \\
\text { N } \\
\text { N }\end{array}$ & 57.46 \\
\hline
\end{tabular}

Tabla 1, de construcción propia en base a la información proporcionada por INEGI [3]

El estudio "Panorama de la Educación", realizado anualmente por la Organización para la Cooperación y el Desarrollo Económico (OCDE), revela que las personas con educación superior aún son acreedores a una sustancial rentabilidad de su inversión:tienen $10 \%$ más de probabilidades de ser empleados y ganan $56 \%$ más en promedio que los adultos que sólo concluyeron la educación media superior, en seguida se muestra la tabla en el informe denominado "Panorama de la Educación 2017 vía OCDE”; se muestran las 10 carreras más demandadas en México [4]:

\begin{tabular}{|c|l|c|}
\hline Posición & Carrera & $\begin{array}{c}\text { Ingreso } \\
\text { Mensual }\end{array}$ \\
\hline 1 & Finanzas, Banca y Seguros & $19,929.00$ \\
\hline 2 & Minería y Extracción & $19,838.00$ \\
\hline 3 & Servicios de Transporte & $18,760.00$ \\
\hline 4 & $\begin{array}{l}\text { Ingeniería de Vehículos de } \\
\text { Motor, Barcos y Aeronaves }\end{array}$ & $14,036.00$ \\
\hline 5 & Literatura & $13,884.00$ \\
\hline 6 & Medicina & $13,403.00$ \\
\hline 7 & Construcción e Ingeniería & $12,933.00$ \\
\hline 8 & Civil & $12,434.00$ \\
\hline 9 & Quísica & $12,271.00$ \\
\hline 10 & Arquitectura y Urbanismo & $12,216.00$ \\
\hline
\end{tabular}

Tabla 2, de construcción propia; Fuente: Observatorio Laboral STPS [4]

En el caso de lo publicado por INEGI, se tiene la siguiente tabla, en la que se muestra el comportamiento de la población en México y su situación ocupacional.

\begin{tabular}{|c|c|c|}
\hline Indicador & Total & $\%$ \\
\hline Población total & $123,364,426$ & 100.00 \\
\hline $\begin{array}{l}\text { Población de } 15 \\
\text { años y más }\end{array}$ & $91,119,098$ & 73.86 \\
\hline $\begin{array}{l}\text { Población } \\
\text { económicamente } \\
\text { activa (PEA) }\end{array}$ & $54,068,791$ & 43.83 \\
\hline Ocupada & $52,198,611$ & 42.31 \\
\hline Desocupada & $1,870,180$ & 1.52 \\
\hline $\begin{array}{l}\text { Población no } \\
\text { económicamente } \\
\text { activa (PNEA) }\end{array}$ & $37,050,307$ & 30.03 \\
\hline Disponible & $5,802,113$ & 4.70 \\
\hline No disponible & $31,248,194$ & 25.33 \\
\hline 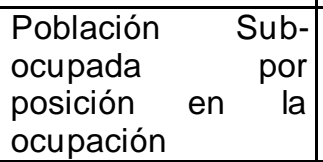 & $3,773,194$ & 3.06 \\
\hline $\begin{array}{l}\text { Trabajadores } \\
\text { subordinados } \\
\text { remunerados }\end{array}$ & $1,802,306$ & 1.46 \\
\hline Empleadores & 186,020 & 0.15 \\
\hline $\begin{array}{l}\text { Trabajadores por } \\
\text { cuenta propia }\end{array}$ & $1,559,745$ & 1.26 \\
\hline $\begin{array}{l}\text { Trabajadores no } \\
\text { remunerados }\end{array}$ & 225,123 & 0.18 \\
\hline
\end{tabular}

Tabla 3, comportamiento de la Población Económicamente Activa y la Población Económicamente no Activa, De construcción propia basada en la información de INEGI [3].

Como ya se ha visto en distintas publicaciones, existen profesiones que encabezan los rankings de salario, y esto no depende de los cambios estructu rales de los gobiemos o las empresas. La OCDE refiere a una afirmación que los nuevos empleos en países desarrollados lo fundamentan en el conocimiento, dicho de otra manera, podrán ser empleados aquellos profesionistas con capacidades técnicas, formación práctica, habilidades directivas y sobre todo con un espíritu emprendedor.

El emprendedor no debe perder de vista la objetividad de lograr o hacer cambiar las cosas en cuanto la formación de empresas, o desarrollarlas, esto conforme a sus 
valores y su propia ética, dirigiendo su esfuerzo hacia la exigencia de la problemática actual de competitividad y globalización, es necesario dominar sus principios teóricos y su tecnología ampliamente confirmada por los países desarrollados [5].

Por lo que Según un informe mundial sobre remuneraciones de la consultora Towers Perrin, el ingreso total anual de un director general en México, incluyendo sus bonos y prestaciones, puede superar los 960,000 dólares. La tesis de que México ofrece sueldos competitivos se confirma con un informe publicado por la revista América Economía, realizado con información de la consultora Price Waterhouse Coopers, el cual revela, por ejemplo, que un gerente o director con alto rango puede obtener en promedio 17,880 dólares por mes, ubicándose por encima de Chile, donde el pago por el mismo puesto es de unos 14,074 dólares [6].

Según lo publicado por la CNN Expansión (Expansión, 2017), En México "para los recién egresados hay puestos hasta de 15,000 pesos, cuando el este reúne ciertas habilidades atractivas para los reclutadores, como el dominio de idiomas. Lo importante para todo esto se adquirir experiencia lo antes posible, incorporarse a las empresas desde los primeros semestres, para poder terminar una carrera con cierta experiencia [7].

\section{CONCLUSIONES}

La forma más idónea de buscar emplear a los profesionistas egresados de una IES, es a través de la aplicación de un esquema o modelo que permita distinguir algunos pasos para lograr el emprendimiento, situación que seguramente harán que el profesionista logre el autoempleo basando su idea en la formación profesional que ha elegido, que reciba el apoyo a través de una asesoría profesiográfica, y que con ello podrá lograr visualizarse siempre bajo el esquema de formarse primero: como profesionista con un perfil de egreso bien definido y con alternativas de aplicarse en su ramo o especialidad estudiada, pero siempre teniendo una alternativa plenamente identificada con la función de un emprendedor, tanto para su desarrollo de su propiafuente de ingresos, como con la consultoría y con miras a apoyar a otros profesionistas que no logran encausar de manera correcta su perfil de egreso.

\section{Referencias}

[1] MCO. (08 de 11 de 2017). http://imco.org.mx. Obtenido de http://imco.org.mx/temas/compara-carreras-2017/\#_ftnref2.
[2] OCDE. (14 de Nov de 2017). Nota País/. Obtenido de http://www.oecd.org:http://www.oecd.org/edu/skills-beyondschool/EAG2017CN-Mexico-Spanish.pdf.

[3] INEGI. (02 de Nov de 2017). http;//www.inegi.org.mx. Obtenido de http;//www.inegi.org.mx/est/contenidos/proyectos/encuestas/hogares/r egulares/enoe/default.aspx.

[4] (31 de 10 de 2017). FORBES México. Obtenido de https://www.forbes.com.mx/las-10-carreras-mejor-pagadas-en-mexico/

[5] G. C. Victoriano (2010). Metodología para el logro Exitoso de la Formación de Directivos Emprendedores, Lima Perú: UNMSM (Universidad NacionalMayor de San Marcos Fondo Editorial).

[6] Coopers, P. W. (28 de Nov de 2017). http://www.pwc.coml. Obtenido de http://www.pwc.com/mx/es/index.jhtml.

[7] Expansión, C. (29 de Octubre de 2017). http://www.cnnexpansion.com/nocticia s/2015/05/19/la-productividadpor-delante. 